Relationships between mycobiont identity, photobiont specificity and ecological preferences in the lichen genus Peltigera (Ascomycota) in Estonia (northeastern Europe)

Juriado, Inga

2019-06

Juriado , I , Kaasalainen , U , Jylhä , M J \& Rikkinen , J 2019 , ' Relationships between mycobiont identity, photobiont specificity and ecological preferences in the lichen genus Peltigera (Ascomycota) in Estonia (northeastern Europe) ' , Fungal Ecology, vol. 39 , pp. 45-54 . https://doi.org/10.1016/j.funeco.2018.11.005

http://hdl.handle.net/10138/309419

https://doi.org/10.1016/j.funeco.2018.11.005

cc_by_nc_nd

acceptedVersion

Downloaded from Helda, University of Helsinki institutional repository.

This is an electronic reprint of the original article.

This reprint may differ from the original in pagination and typographic detail.

Please cite the original version. 


\section{Relationships between mycobiont identity, photobiont specificity and ecological preferences in the lichen genus Peltigera (Ascomycota) in Estonia (northeastern Europe)}

Inga Juriado ${ }^{a, *}$, Ulla Kaasalainen ${ }^{b}$, Maarit Jylha ${ }^{c}$, Jouko Rikkinen ${ }^{b, c}$

a Institute of Ecology and Earth Sciences, University of Tartu, Lai 38/40, Tartu, 51005, Estonia

b Finnish Museum of Natural History, University of Helsinki, P.O. Box 7, 00014, Helsinki, Finland

c Organismal and Evolutionary Biology Research Programme, Faculty of Biological and Environmental Sciences, University of Helsinki, P.O. Box 65, 00014, Helsinki, Finland

\section{A B S T R A C T}

We studied the genotype diversity of cyanobacterial symbionts in the predominately terricolous cyanolichen genus Peltigera (Peltigerales, Lecanoromycetes) in Estonia. Our sampling comprised 252 lichen specimens collected in grasslands and forests from different parts of the country, which represented all common Peltigera taxa in the region. The cyanobacteria were grouped according to their tRNALeu (UAA) intron sequences, and mycobiont identities were confirmed using fungal ITS sequences. The studied Peltigera species associated with 34 different "Peltigera-type" Nostoc $\operatorname{trnL}$ genotypes. Some Peltigera species associated with one or a few trnL genotypes while others associated with a much wider range of genotypes. Mycobiont identity was the primary factor that determined the presence of the specific Nostoc genotype within the studied Peltigera thalli. However, the species-specific patterns of cyanobiont selectivity did not always reflect phylogenetic relationships among the studied fungal species but correlated instead with habitat preferences. Several taxa from different sections of the genus Peltigera were associated with the same Nostoc genotype or with genotypes in the same habitat, indicating the presence of functional guild structure in the photobiont community. Some Nostoc trnL genotypes were only found in the Peltigera species of moist and mesic forest environments, while another set of Nostoc genotypes was typically found in the Peltigera species of xeric habitats. Some Nostoc trnL genotypes were only found in the Peltigera taxa that are common on alvars and may have specialized to living in this unusual and threatened habitat type. 


\section{Introduction}

Lichen symbioses always include at least one primary fungal symbiont, the mycobiont, and one or more photosynthetic partners, the photobionts. The photobionts of bipartite lichens are either green algae or cyanobacteria, while tripartite lichen thalli include both major types of photobionts (Rikkinen, 2002; Henskens et al., 2012). Besides the primary mycobiont and the photobionts, also many associated fungi and bacteria take part in lichen-symbiotic consortia (Grube et al., 2009; Sigurbjornsdottir et al., 2015; Aschenbrenner et al., 2016; Grube and Wedin, 2016; Spribille et al., 2016).

Approximately $10 \%$ of all known lichen-symbiotic fungi associate with cyanobacterial photobionts (Rikkinen, 2015, 2017). Most fungi in the order Peltigerales (Ascomycota) invariably associate with cyanobacteria, most commonly with symbiotic representatives of Nostoc (Nostocales). These fungi include all species of Peltigera (Vitikainen, 1994, 2007). Lichen-symbiotic Nostoc cannot presently be named to species, but symbiotic genotypes can be identified by using DNA markers such as the cyanobacterial trnL intron, rbcLX and 16S rDNA genes (Rikkinen, 2013; Kaasalainen et al., 2015; Joneson and O'Brien, 2017; Magain et al., 2017a).

Some of the earliest molecular studies on cyanolichens focused on the Nostoc cyanobionts of Peltigera in northern Europe and western North America (Paulsrud et al., 1998, 2000, 2001). In these studies, only one Nostoc genotype was typically detected in each bipartite Peltigera thallus and in different cephalodia of the tripartite Peltigera species. These findings have not been challenged by the results of more recent studies, with the exception that some tripartite Peltigera species have sometimes been found to house different Nostoc genotypes within different cephalodia of single thalli (Paulsrud et al., 2000; Kaasalainen et al., 2009; Rikkinen, 2013). Several studies on green algal lichens, have challenged the dogma of single photobiont genotypes or taxa within a single lichen thallus, and suggest the presence of mixed photobiont populations in many cases (e.g. Guzow-Krzeminska, 2006; Casano et al., 2010; Onuț;-Brannstrom et al., 2018). However, Paul et al. (2018) compared Sanger sequencing and high-throughput sequencing for determining photobiont diversity in lichens and proposed that Sanger technology consistently yields the most abundant photobiont sequence in the lichen sample.

The level of photobiont specificity in lichen-forming fungi can be determined by elucidating the number of photosynthetic partners that are utilized by one mycobiont species (Yahr et al., 2006; Otalora et al., 2010; Magain et al., 2017a). The symbiont specificity expressed by lichenforming fungal species and their main photobionts varies widely and they range from strict 
specialists, i.e. those associating with only one species, through moderate specialists, i.e., those associating consistently with a few species, to broad generalists, i.e. those associating with many different species with little or no apparent selectivity (Magain et al., 2017a; Lu et al., 2018). The fact that lichen mycobionts generally tend to associate with only one or a few photobiont genera (green algae or cyanobacteria), suggests inherent deep phylogenetic constraints in partner compatibility (Rolshausen et al., 2018). In rare cases, single mycobionts can form different lichen morphotypes in symbiosis with compatible green algal and cyanobacterial photobionts, respectively, and such disparate morphs can either combine into one compound thallus or live separately (Rikkinen, 2015).

The patterns of photobiont specificity are scale dependent regarding the various phylogenetic scales (e.g. genotype, species or higher taxonomical levels) and as well as the spatial scale. An analysis of photobiont association patterns within the green algal lichen family Parmeliaceae at the scale of ecoregions indicated that the generic identity of fungal hosts was a better predictor of photobiont association than ecological predictors (Leavitt et al., 2015). Likewise, a study of photobiont specificity in Peltigera section Polydactylon revealed very high specificity even at the smallest spatial scales analysed (Chagnon et al., 2018).

However, according to several studies on green algal lichens (Fernandez-Mendoza et al., 2011; Sadowska-Deś et al., 2014; Leavitt et al., 2015, 2016; Williams et al., 2017), climatic factors can also play a role in shaping photobiont distributions and association patterns, even at a global scale (Singh et al., 2017; Magain et al., 2017a). While reciprocal (one-to-one) specificity by both symbiotic partners has been reported for some mycobionts (Otalora et al., 2010; Magain et al., 2017a, b), many fungal species associate with several different Nostoc (Fedrowitz et al., 2012; Magain et al., 2017a), or Trebouxia haplotypes (Leavitt et al., 2015). It is suggested that association patterns among lichen symbionts at a very fine level would be environmentally structured rather than phylogenetically constrained and switching between photobiont ecotypes with distinct environmental preferences has been hypothesized as an adaptive strategy for lichen-forming fungi (Rikkinen, 2003; Rolshausen et al., 2018). Photobiont switches within a single fungal species have indeed been identified along both latitudinal and altitudinal gradients (Muggia et al., 2008; Fedrowitz et al., 2012; Vargas Castillo and Beck, 2012; Magain et al., 2017a; Dal Grande et al., 2018).

Although community scale patterns of photobiont diversity are most likely influenced by the environment, few molecular studies have so far addressed ecological segregation between closely 
related lichen photobionts. Distinguishing the influence of different ecological factors on photobiont populations or on mycobiont selectivity is complicated by the fact that many ecological factors tend to be strongly intercorrelated. In green algal lichens the role of habitat or substratum as a determinant of the photobiont type seems to vary among different lichens and environments (Beck et al., 2002; Blaha et al., 2006; Muggia et al., 2008, 2013; Leavitt et al., 2013). For example, Peksa and Škaloud (2011) found that the green algal photobionts of the crustose lichen Lepraria (Lecanorales) were clearly differentiated based on their substrate and climatic preferences; the photobionts of the epiphytic pendulous lichen Ramalina menziesii showed significant structure according to the ecoregion and phorophyte species (Werth and Sork, 2014); and photobionts associating with the epigeic fruticose lichen Cladonia subtenuis exhibited population subdivision according to the ecoregion and habitat (Yahr et al., 2006). There is evidence that the substratum of lichenized fungi can play some role in determining photobiont association patterns (e.g. Elvebakk et al., 2008), although others have suggested that differences in substrate preferences do not have major influence (O'Brien et al., 2005, 2013; Stenroos et al., 2006; Otalaora et al., 2010). Ortiz-Alvarez et al. (2015) found that the selection of cyanobacterial photobionts in two closely related maritime species of Lichina (Lichinales) was linked to contrasting environmental conditions in their closely situated coastal niches.

Several studies have indicated that species of lichen-forming fungi that only reproduce sexually are often less selective in their choice of photobionts compared to related fungi that reproduce via symbiotic diaspores (Blaha et al., 2006; Otalora et al., 2010, 2013; Fedrowitz et al., 2012; Muggia et al., 2013, 2014; Leavitt et al., 2015). At the community scale, functional lichen guilds exist in which appropriate photobiont genotypes are shared among coexisting mycobiont species and in some cases even between fungi and bryophyte hosts (Costa et al., 2001; Rikkinen, 2002, 2017; Rikkinen et al., 2002; Rikkinen and Virtanen, 2008; Lucking et al., 2009; Dal Grande et al., 2014; Cornejo and Scheidegger, 2016). Lichen guilds can involve mycobiont species with different dispersal modes: core species can effectively disperse photobionts in symbiotic diaspores, while sexually reproducing fringe species can benefit from this activity (Rikkinen, 2003).

Our recent analysis of 252 Peltigera specimens from different habitats in Estonia revealed 31 putative fungal taxa (OTUs), confirming that the genus includes many insufficiently known species (Juriado et al., 2017). Multivariate analysis revealed habitat-specific segregation between the different species along a gradient from humid eutrophic forests to dry oligotrophic forests and grasslands and along a soil pH gradient from alkaline soils of alvar grasslands to acidic soils of 
conifer forests. The species diversity of Peltigera was the highest on roadsides and dunes and the lowest in alvar habitats, which supported a unique assemblage of undescribed taxa. Deciduous broad-leaved forests, too, included several undescribed or rare and red-listed species, demonstrating that many Peltigera species have narrow habitat requirements and are threatened by habitat loss and degradation (Juriado et al., 2017).

Here we extend our treatment of Estonian Peltigera species through analysing a large new dataset of their Nostoc photobionts. The cyanobacterial photobiont (cyanobiont) of each lichen specimen was determined by using cyanobacterial tRNALeu (UAA) intron (trnL) sequences as a genetic marker. As trnL is easy to amplify and shows sufficient variability, especially in the P6b region, it has been widely employed for DNA based identification of symbiotic Nostoc genotypes (e.g. Paulsrud et al., 1998, 2000, 2001; Fedrowitz et al., 2011, 2012; O'Brien et al., 2005, 2013). In addition, the more conserved parts of $\operatorname{trn} L$ intron have been used to assess phylogenetic relationships, often alongside the $16 \mathrm{~S}$ rRNA gene and other markers (e.g. Summerfield et al., 2002; Kaasalainen et al., 2015).

To determine possible correlations between habitat specificity and photobiont selectivity, we compared photobiont diversity in Peltigera specimens collected from different habitat types and substrata, including grassland and forest types. We hypothesize that cyanobacterial photobionts are not randomly distributed along the complex environmental gradient, but their distributions correlate both with identity of the mycobiont as well as with growth conditions.

\section{Material and methods}

\subsection{Study region and sampling}

Lichen specimens were collected in 2012-2016 from 107 localities in Estonia; some additional specimens from the collections of the University of Tartu (TU) were also included in the study. The study sites were distributed over the whole country and represented three wooded habitat types (oligotrophic forests, eutrophic forests, and park stands) and three grassland types (alvars, dunes, and roadsides). In addition to the habitat type, each lichen specimen was assigned one of three substratum types (tree, rock, and ground). For additional information on the field sites and sampling, see Juriado et al. (2017). 
In ecological analyses, the substratum and the habitat variables were combined ('ground_alvar', 'ground_dune', 'ground_eutrophic forest', 'tree_eutrophic forest', 'rock_roadside', 'rock_eutrophic forest' etc.). The habitats collectively represent a natural gradient of decreasing atmospheric humidity from grasslands to mesotrophic forest, and increasing soil $\mathrm{pH}$, from acidic soils of oligotrophic forest to basic alvar grassland soils. At each study site, up to three specimens of each morphologically distinguishable Peltigera taxon were collected for DNA analysis. Phylogenetic analyses of Internal Transcribed Spacer (ITS) sequences allowed to delimit 31 putative Peltigera taxa (OTUs) of 252 Peltigera specimens, some of them undescribed (e.g. $P$. "neorufescens", P. "fuscoponojensis", P. "neocanina", Juriado et al., 2017).

\subsection{Molecular data}

Well-developed lobes of Peltigera thalli without visible symptoms of fungal infection were selected for molecular analyses. For DNA extraction, tiny thallus fragments containing both the cyano- and mycobiont from terminal parts of the lobes were placed under a dissecting microscope. DNA was extracted using the GeneJET Genomic DNA Purification Kit (Thermo Scientific) following the manufacturer's protocol for Gram-Negative Bacteria. Amplification of cyanobacterial trnL was performed with the primer pair tRNA Leu outF and tRNA Leu outR (Paulsrud and Lindblad, 1998). The amplification reaction was prepared for a $50-\mu l$ final volume containing $2 \mu$ l genomic DNA, $37.5 \mu$ l of sterile distilled water, $5 \mu$ l of 10xreaction buffer, $1 \mu$ dNTP (10mM), $1 \mu$ l tRNALeu outF (50mM), $1 \mu$ l tRNALeu outR (50mM), $1.25 \mu \mathrm{l}$ BSA (20mg/ml) (Thermo Scientific) and $1.25 \mu$ l Dynazyme II ( $2 \mathrm{U} / \mu \mathrm{l})$ (Thermo Scientific). The heating cycle was the following: initial denaturation of 3 minat $94{ }^{\circ} \mathrm{C}$ followed by 4 cycles of $30 \mathrm{~s}$ at $94{ }^{\circ} \mathrm{C}, 30 \mathrm{~s}$ at $55^{\circ} \mathrm{C}$, and 2 minat $72{ }^{\circ} \mathrm{C}$. This was followed by 26 cycles of $30 \mathrm{~s}$ at $94{ }^{\circ} \mathrm{C}, 30 \mathrm{~s}$ at $60{ }^{\circ} \mathrm{C}$, and 2 minat $72{ }^{\circ} \mathrm{C}$, with a final extension of 10 minat $72{ }^{\circ} \mathrm{C}$. The amplification products were purified with the GeneJET PCR Purification Kit (Thermo Scientific). Sequencing was performed by Macrogen Inc. in Europe with the same primers. The chromatograms of all sequences were checked and aligned using the program CodonCode Aligner 6.0.2 (CodonCode Corporation, Dedham, MA, USA). The alignment of the entire tRNALeu intron sequences (354-374 bp) was used in the analyses. All newly obtained sequences are deposited in the European Nucleotide Archive (http:// www.ebi.ac.uk/ena/ data/view/LS998801-LS999057) (Table S1). The mycobiont ITS sequences of the same lichen sample are stored in the NCBI GenBank database (LT852805-LT853056) (Juriado et al., 2017). The 
voucher specimens are deposited in the lichenological herbarium of the Natural History Museum at the University of Tartu (TU).

\subsection{Data analyses}

The program Network 5.0.0.1 (Bandelt et al., 1999) was used to reconstruct the median-joining networks of the Nostoc trnL genotypes based on nucleotide differences in the trnL sequences. The Nostoc genotypes are denoted by letters and numbers (Fig. 1). Different letters were assigned to genotypes that differ by a minimum of 6 nucleotides. To illustrate the associations between the cyanobiont trnL genotypes and the fungal OTUs, a bipartite interaction network was constructed using R 3.3.3 (R Core Team, 2017) and the 'bipartite' package (Dormann et al., 2008). By using the program DnaSP 5.10 .01 (Librado and Rozas, 2009), the diversity of the Nostoc trnL genotypes among the substratum-habitat groups was calculated.

Variation partitioning analysis (VPA) in the program package CANOCO 5 (ter Braak and Šmilauer, 2012; Šmilauer and Lepš, 2014) was employed to partition variation in the symbiotic Nostoc genotypes associated with the studied Peltigera samples. Rare Nostoc genotypes appearing only once or twice in the dataset were removed prior to analysis. Two subsets of explanatory variables ('Mycobiont species' and 'Habitat') were used to test the unique effects of both variable sets and the shared proportion of variation explaining the distribution of the Nostoc genotypes. 'Mycobiont species' represented 18 Peltigera taxa, including widely used traditional species and some undescribed taxa (i.e. P. "neorufescens", P. "fuscoponojensis", P. aff. "neocanina" according to Juriado et al., 2017, Table S1). The variable set 'Habitat' included the combined substratum and habitat variables. Significance was assessed using permutation tests.

The symmetric co-correspondence analysis (symmetric CoCA, ter Braak and Schaffers, 2004) in the program package CANOCO 5 was used to relate two different kinds of biotic community (i.e. Peltigera taxa and Nostoc trnL genotypes) recorded over identical sets of locations. CoCA finds the ordination axes (gradients) along which the weighted co-variance among case scores for the two compared communities is maximized. Statistically significant compositional co-variation between the two communities is tested by the permutation test. Effectiveness of the ordination is expressed by eigenvalues (variance in the community matrix attributed to a particular axis) and by total inertia (sum of the eigenvalues or total "variance" in the species data). The environmental variables were used as supplementary variables to help describe the ecological gradients that were common for both communities. The delimitation of the mycobiont taxa follows the 
description in Juriado et al. (2017). Rare taxa, appearing only once or twice in the dataset, and redundant specimens from the same site with identical mycobiont and photobiont sequences were removed prior to analysis. As a result, 22 Peltigera taxa were obtained, which were used in the first step of ordination analyses (Table S1). In the second step of ordination analysis, three taxa were excluded as the outliers.

\section{Results}

\subsection{Distribution of Nostoc genotypes in different habitats}

In total, 244 Nostoc trnL sequences were obtained from the 252 sampled Peltigera specimens (Tables S1 and S2). Most of these sequences (229) had a Class 2 repeat motif in the P6b region (Costa et al., 2002; Kaasalainen et al., 2015) and represented 30 different Nostoc genotypes (genotypes A1-A23, B, C1-C3, D, J, K in Fig. 1).

Fifteen sequences of Nostoc from four Peltigera species had a Class 1 repeat motif in the P6b region (Costa et al., 2002; Kaasalainen G, H in Fig. 1). Three Nostoc genotypes (B, A1 and A2) were very common and widely distributed, accounting for 24, 21 and 18 percent of all sequences, respectively. Nearly half (47\%) of all Nostoc sequences, from less than 10 Peltigera thalli, belonged to the other genotypes, with 15 Nostoc genotypes found only once.

Genotypes A1 and A2 were very similar, differing in only one nucleotide site (Fig. 1). These two genotypes, like many other highly similar Nostoc genotypes marked with letter A, were largely confined to terricolous Peltigera species. Genotype A1 was most commonly found in Peltigera specimens from alvars (37\%), dunes (29\%), and roadside grasslands (14\%). Genotype A2 was most commonly found in Peltigera specimens from dunes (30\%), oligotrophic forest (22\%), and parks (18\%). Genotypes A3 and A4 were found mostly, and genotypes A10, A14, A17 and A20, exclusively, in the lichens growing on alvar grasslands (Fig. 1). Genotypes A7, A12 and A16 were only found in lichens from dunes, and genotypes A5, A13 and A12 were only found from lichens from roadsides (Fig. 1). Nostoc genotype D was largely restricted to terricolous Peltigera species that grew in oligotrophic forests and on dunes (Fig. 1).

A substantial majority (66\%) of the sequences representing Nostoc genotype B were obtained from Peltigera specimens growing on mossy tree bases or on logs in eutrophic forests. Another $12 \%$ of these sequences were obtained from lichens of mossy rocks in park stands and 
still another $12 \%$, from lichens growing on ground in eutrophic forests. Also Nostoc genotypes C1, C2 and C3 were obtained from eutrophic forests and park stands, where they were mainly found in Peltigera taxa that grew on mossy rocks or ground (Fig. 1). Nostoc genotypes E, F, G, H with a Class 1 repeat motif in the P6b region, were found mostly in Peltigera species growing on the ground in dunes, parks, roadsides and oligotrophic forests as well as on mossy rocks in the same habitats (Fig. 1).

Among all studied substrata in the different habitat types, the total number of symbiotic Nostoc genotypes was the largest in Peltigera species that grew on the ground in alvar grasslands and on dunes. However, the diversity values recorded for the roadsides as well as for the ground and rock in eutrophic forests were even slightly higher (Table 1). The smallest number of Nostoc genotypes and the lowest genotype diversity values were recorded for tree bases in eutrophic forests (Table 1).

\subsection{Distribution of Nostoc genotypes in different Peltigera taxa}

The bipartite interaction network (Fig. 2) shows associations between the different Peltigera species and different Nostoc genotypes. Nostoc genotype A1 was found in 13 different Peltigera taxa (OTUs), most frequently in P. "neorufescens" and P. rufescens (Table S1). Nostoc genotype A2 was found from 15 different Peltigera taxa, most frequently in $P$. rufescens and $P$. canina s. lat. (Table S1). Most species of the Peltigera section Peltigera associated with these two genotypes, but also P. leucophlebia (section Chloropeltigera) and P. neckeri (section Horizontales), associated with the same two Nostoc genotypes (Table S1, Fig. 2). As a whole, all Nostoc genotypes assigned with letter A (A1-A23) had similar distributions among the same set of Peltigera species.

Nostoc genotype B was found in eight different Peltigera taxa, most commonly $P$. polydactylon (section Polydactylon), P. praetextata, P. canina II and III, and P. aff. neocanina (section Peltigera). Nostoc genotype C2 was only found in P. degenii (section Peltigera) and $P$. neopolydactyla (section Polydactylon). Peltigera membranacea (section Peltigera) associated with Nostoc genotype C1 and P. hymenina (section Polydactylon) associated with genotypes C1 and C3. Nostoc genotype D was mostly found in P. extenuata and in one case in P. didactyla. Peltigera aphthosa and P. malacea (section Peltidea) always associated with Class 1 type Nostoc genotypes ( $E$ and $F$, respectively), and the sole specimen of $P$. collina had its own, unique Nostoc genotype. (Table S1, Fig. 2). 


\subsection{Relationships between Peltigera taxa, Nostoc genotypes and ecological factors}

The results of variation partitioning analysis (VPA) showed that the two variable sets ('Mycobiont identity' and 'Habitat') together explained $65.3 \%$ of the variation in the symbiotic Nostoc genotypes associated with different Peltigera taxa (Table 2). The identity of mycobiont species was the most important factor, explaining $45.6 \%$ in the total variation. Of the total variation, $7.2 \%$ was explained by the habitat, while the co-effect of mycobiont identity and habitat type explained $12.6 \%$ of the total variation.

Permutation tests revealed that the relationship between the Peltigera taxa and symbiotic Nostoc genotypes in symmetric co-correspondence analysis CoCa was significant $(p=0.004)$ for all ordination axes. The cross-correlation values of the first two ordination axes were 0.91 and 0.94 and the corresponding eigenvalues were 0.71 and 0.59 , respectively. The total inertia values (the sum of all eigenvalues) for the Peltigera taxa and the Nostoc genotypes were 11.2 and 12.5, respectively. The response scores are presented in the dual ordination diagrams of the CoCa axes of Fig. 3. Also the environmental variables are presented as overlays on the subplots.

Peltigera degenii (Fig. 3, subplot A) occurred in eutrophic forests and park stands and associated with Nostoc genotype C2 (Fig. 3, subplot B). Peltigera membranacea and P. hymenina occurred mainly on ground or mossy stones in eutrophic forests (Fig. 3, subplot A) and associated most frequently with Nostoc genotypes C1 and C3, respectively (Fig. 3, subplot B). As these three Peltigera species differed clearly from all the rest with respect to both habitat preferences and cyanobiont composition (Figs. 1 and 3), they were excluded from the next step of the ordination analysis (Fig. 4).

Also in the second CoCA analysis, permutation tests revealed that the relationship between the Peltigera taxa and symbiotic Nostoc genotypes was significant $(p=0.003)$ for all ordination axes. The cross-correlation values of the first two ordination axes were 0.89 and 0.78 and the corresponding eigenvalues were 0.65 and 0.36 , respec tively. The total inertia values for the Peltigera taxa and for the Nostoc genotypes were 10.7 and 12.1, respectively. The response scores are presented in the dual ordination diagrams of the CoCa axes of Fig. 4. Also the environmental variables are presented as overlays on the sub-plots.

Peltigera polydactylon grew on mossy tree trunks in eutrophic forests (Fig. 4, subplot A) and associated only with Nostoc genotype B (Fig. 4, subplot B). Also P. aff. "neocanina", P. praetextata, $P$. canina II, P. canina III and $P$. didactyla II grew mainly on tree bases and mossy rocks in eutrophic forests (Fig. 4, subplot A) and associated with the same Nostoc genotype B (Fig. 3, subplot B). 
Peltigera extenuata grew on soil in oligotrophic forests and on dunes (Fig. 4, subplot A) and always associated with its own Nostoc genotype D.

Most terricolous Peltigera taxa that grew in park stands, oligotrophic forests, dunes, and roadsides, incl. P. canina I, P. didactyla I and III, P. neckeri (Fig. 4, subplot A), associated mostly with a group of closely related Nostoc genotypes, most commonly the frequent genotype $A 2$, but also A1, A3, A9 and A12 (Fig. 4, subplot B). Peltigera "fuscoponojensis", P. ponojensis I and II, and P. rufescens (Fig. 4, subplot A) associated with the same group of closely related Nostoc genotypes, most commonly the frequent genotype A1 (Fig. 4, subplot B). Peltigera "neorufescens" and $P$. "neorufescens" agg. III grew only on alvar grasslands (Fig. 4, subplot A) and always associated with their own distinct selection of Nostoc genotypes (Fig. 4, subplot B).

\section{Discussion}

The degree of photobiont specificity of cyanolichen-forming fungi belonging to different taxonomic groups has been extensively studied. For cyanolichens with Nostoc cyanobionts, the results have been quite variable depending on the set of taxa studied (e.g. Paulsrud et al., 2000; Myllys et al., 2007; Elvebakk et al., 2008; Otalora et al., 2010; Fedrowitz et al., 2012; Ortiz-Alvarez et al., 2015; Magain et al., 2017a,b). Some Peltigera species seem to be highly specialized and only associate with one or a few selected photobiont genotypes, while others are more promiscuous and associate with a range of different Nostoc genotypes (e.g. Paulsrud et al., 1998, 2001; O'Brien et al., 2005, 2013; Miadlikowska et al., 2014; Zuniga et al., 2015; Magain et al., 2017a; Chagnon et al., 2018). Some widely distributed Peltigera species can associate with different Nostoc cyanobionts in different parts of their range (Manoharan-Basil et al., 2016; Magain et al., 2017a). Thus, photobiont specificity may often be scale-dependent, and a strict specificity detected at a local scale does not necessarily hold on larger geographical scales (Magain et al., 2017a; Lu et al., 2018). These general patterns were also evident in our data set, with some Estonian Peltigera species (e.g. $P$. ponojensis, $P$. rufescens, $P$. neckeri) associated with several Nostoc genotypes while other species (e.g. P. aphthosa, P. malacea, P. extenuata, P. polydactylon) were always confined to one specific Nostoc genotype.

Many of the Nostoc trnL genotypes detected in Estonian Peltigera specimens are new; others have previously been found from other parts of Europe. For example, the three Nostoc 
genotypes (A1, A2, B) that were most frequently found in Estonia were previously known from other regions. According to the sequences in GenBank, Nostoc genotypes A1 and A2 have previously been found in cephalodia of Peltigera leucophlebia in southern Norway, and in Peltigera canina in Spain and in Poland; Nostoc genotype A2 has been found also in a Peltigera rufescens specimen in southern Finland (Table S3). Nostoc genotype B has been detected repeatedly in different Peltigera species in Europe, typically in taxa that grow on forest soil, rotten logs, or bryophyte covered tree trunks (Table S3). Even more interestingly, sequences of identical Nostoc cyanobionts have also been found in western North America and East Asia, indicating that this Nostoc genotype is widely distributed in suitable habitats across the boreal and temperate zones of the northern hemisphere. Also the rare Nostoc genotypes, for example Nostoc genotype F, which was found in Peltigera malacea specimens in Estonia, has previously been detected in the same Peltigera species in central Finland (Kaasalainen et al., 2015). Nostoc genotype K from Peltigera collina has previously been found in the same species in Scotland and has also been cultured from Lobaria pulmonaria and epiphytic mosses in central Finland (Rikkinen et al., 2002; Fedrowitz et al., 2012). Nostoc genotype E from Peltigera aphthosa specimens has previously been found in Nephroma arcticum in northern Finland (Fedrowitz et al., 2012).

One may expect that many of the novel Nostoc genotypes now reported from Estonia are more widely distributed than presently known. Sampling in most previous studies has mainly focused on the muscicolous Peltigera species of boreal forests and bordering temperate and subalpine habitats, while the terricolous Peltigera communities of calcareous soils have not received equal attention. Hence, the Nostoc cyanobionts of the lichens of such habitats are probably underrepresented in GenBank and other databases. This finding is in accordance with the overall bioclimatic conclusions of Magain et al. (2017a) and suggests co-specialization between certain mycobionts and cyanobionts that are both specifically adapted to living on calcareous soils in temperate regions.

Our current findings demonstrate that mycobiont identity is the most important factor determining the presence of a specific Nostoc genotype within the Peltigera thallus. However, also an independent effect of the habitat was detected. The habitat specific spectra of different Peltigera taxa in different habitat types explained a major proportion of variation in the distribution of symbiotic Nostoc genotypes. For example, P. canina II and III, growing on tree bases and logs, were more likely to associate with Nostoc genotype B than with any of the other Nostoc genotypes that were typically found in soil-dwelling members of the Peltigera canina group. A 
similar pattern of substrate specific selectivity was also detected in $P$. didactyla s. lato. Thus, specimens of $P$. didactyla II growing on mossy logs or rock in forests associated with Nostoc genotype B, while terricolous specimens of $P$. didactyla I and III housed different Nostoc genotypes (Fig. 4). Our results indicate that some groups of Nostoc genotypes are largely confined to specific habitat types (e.g. grasslands versus forests) and/or certain substrata (e.g. ground versus tree bases). Such symbionts are shared between closely related fungal taxa, but also between distantly related species representing different sections of the genus Peltigera. For example, in xerophytic habitats there was rampant cyanobiont sharing, not only among terricolous taxa of the section Peltigera (e.g. P. ponojensis and P. rufescens), but also between ecologically similar species from other sections ( $P$. neckeri from Horizontales and $P$. leucophlebia from Chloropeltigera). Another such mixed group of Peltigera species preferred mesic forests and centered on a group of closely related Nostoc genotypes (genotypes C1-C3, Figs. 2 and 3). Their cyanobionts were never found from among the other Peltigera species in the region. As a further example, Nostoc genotype B was common in Peltigera species that grew on mossy tree bases or logs in shaded forest habitats (Figs. 2 and 4). Peltigera polydactylon (section Polydactylon) relied on this Nostoc genotype, and $P$. praetextata and several other taxa of the section Peltigera also frequently housed the same cyanobiont.

The habitat specific selection of the trnL Nostoc genotypes found in this study indicates the presence of a guild structure similar to that found in many other cyanolichens (Rikkinen et al., 2002; Myllys et al., 2007; Elvebakk et al., 2008; Kaasalainen et al., 2013; O'Brien et al., 2013; Joneson and O'Brien, 2017) and green algal lichens (Beck et al., 1998; Peksa and Škaloud, 2011; Dal Grande et al., 2014). Photobiont-mediated guilds are communities of lichenized fungi often occurring in the same habitat, and are horizontally linked through photobiont sharing (Rikkinen, 2003; Dal Grande et al., 2014). In Estonia, certain Nostoc genotypes were shared by Peltigera species that only occurred in mesic forests, while others were shared by species growing on xerophytic open grasslands. Such division of the photobiont association according to the habitat and substratum type indicates that the guild structure is linked not only to the environmental requirements of mycobionts but also to those of the Nostoc cyanobionts. On a functional level, some lichen guilds have been suggested to involve two types of mycobionts: core species that effectively disperse photobionts in their symbiotic diaspores, and fringe species that exploit these photobionts but mainly disperse via fungal spores. Thus, core species can effectively maintain a viable population of photobionts at the local scale, and these photobionts are also exploited and 
incorporated into fringe species via horizontal transmission (Rikkinen et al., 2002; Rikkinen, 2003; Dal Grande et al., 2014). Considering the common occurrence of Nostoc genotype B in Estonian forests, P. praetextata, which often produces symbiotic diaspores (phyllidia), may possibly function as a core species. Other Peltigera species, which also depend on Nostoc genotype B but only reproduce via ascospores, may behave as fringe species that directly benefit from cyanobionts dispersed by $P$. praetextata.

Ramirez-Fernandez et al. (2013) reported that in the Chilean Patagonian region (South America), the diversity of Peltigera cyanobionts was higher in native forests with low or medium disturbance intensity than in grasslands with high disturbance intensity. When comparing the diversity of the symbiotic Nostoc genotype between different habitats and substrata in Estonia, high diversity of Nostoc genotypes associated with Peltigera taxa was found in many different habitats: on ground in roadside grasslands, on dunes or eutrophic forests, and on mossy rocks in eutrophic forests (Table 1).

A comparatively high diversity of Nostoc genotypes was found also associating with Peltigera specimens collected from alvar grasslands. The Estonian grasslands are usually characterized by high soil pH and they support high diversity of different Peltigera taxa (Juriado et al., 2017). The alvars are the most peculiar and extreme grassland habitats in this region, both with respect to soil type and their properties (Koster and Kolli, 2016) and land-use history (Eriksson et al., 2002; Partel et al., 2007). Thin-soil alvars typically support biological soil crusts with highly specific lichen communities (Leppik et al., 2013, 2015; Budel et al., 2014). Two Peltigera taxa (P. "neorufescens" agg.) that were typically found in alvar grasslands (Juriado et al., 2017) are phylogenetically well defined (Miadlikowska et al., 2003; Juriado et al., 2017) and will potentially represent new species. In addition to their preference for nutrient-rich calcareous soil, they seem only to associate with a specific group of Nostoc genotypes (Fig. 4).

A comparatively low diversity of Nostoc genotypes was found in Peltigera specimens collected from mossy tree bases and logs (Table 1). Accordingly, Fedrowitz et al. (2011) found only five closely related Nostoc genotypes in 232 epiphytic Nephroma thalli representing three different species. Such findings may suggest that the pool of compatible Nostoc genotypes on tree trunks or logs may be more limited compared to those occurring on moss-covered rocks, mossy ground or bare soil (Zuniga et al., 2017). On the other hand, epiphytic bryophytes on tree trunks and logs may often act as a reservoir of compatible Nostoc genotypes (e.g. Rikkinen et al., 2002). For example, epiphytic mats of the liverwort Frullania asagrayana harbors lichen symbiotic 
Rhizonema strains and seems to provide nursery beds for the establishment and growth of Erioderma pedicellatum (Cornejo and Scheidegger, 2016).

In conclusion, we established that mycobiont identity was the most important factor determining the presence of specific Nostoc genotypes within the Peltigera thalli. However, the pattern of cyanobiont selectivity also correlated with environmental variables. In eutrophic and mesic forests the widespread and prolific sharing of some Nostoc genotypes between several different Peltigera taxa indicates that guild interactions are important in the habitat ecology of these lichens. The same applies to certain groups of terricolous Peltigera species on calcareous soils, including the two Peltigera species that are adapted to the unique environmental conditions of alvar grasslands. As several phylogenetically defined taxa (Juriado et al., 2017) showed a distinct pattern of Nostoc genotype specificity, which was also in correlation with habitat conditions, our findings of symbiont specificity may help delimit the undescribed species.

\section{Acknowledgments}

Financial support was received from the European Union's Horizon 2020 research and innovation programme under the Marie Sklodowska-Curie grant agreements No 659070 and No 705777; and from Mobilitas Pluss programme (MOBTP66) supported Estonian Research Council and European Regional Development Fund. Special thanks are due to E. Oja, A. Suija, P. Degtjarenko, J. Liira, M.L. Kamara, A. Palo, and T. Randlane for collecting some of the specimens. We are grateful to anonymous reviewers for their valuable comments on the manuscript. E. Jaigma is acknowledged for revising the English text of the manuscript.

\section{Appendix A. Supplementary data}

Supplementary data to this article can be found online at https://doi.org/10.1016/j.funeco.2018.11.005.

\section{References}

Aschenbrenner, I.A., Cernava, T., Berg, G., et al., 2016. Understanding microbial multi-species symbioses. Front. Microbiol. 7, 180. 
Bandelt, H.-J., Forster, P., Röhl, A., 1999. Median-joining networks for inferring intraspecific phylogenies. Mol. Biol. Evol. 16, 37-48.

Beck, A., Friedel, T., Rambold, G. 1998. Selectivity of photobiont choice in a defined lichen community: inference from cultural and molecular studies. New Phytol. 139, 709-720.

Beck, A., Kasalicky, T., Rambold, G., 2002. Myco-photobiontal selection in a Mediterranean cryptogam community with Fulgensia fulgida. New Phytol. 153, 317-326.

Blaha, J., Baloch, E., Grube, M., 2006. High photobiont diversity in symbioses of the euryoecious lichen Lecanora rupicola (Lecanoraceae, Ascomycota). Biol. J. Linn.Soc. 88, 283-293.

Büdel, B., Colesie, C., Green, T.G.A., et al., 2014. Improved appreciation of the functioning and importance of biological soil crusts in Europe e the Soil Crust International project (SCIN). Biodivers. Conserv. 23, 1639-1658.

Cornejo, C., Scheidegger, C., 2016. Cyanobacterial gardens: the liverwort Frullania asagrayana acts as a reservoir of lichen photobionts. Env. Microb. Rep. 8, 352-357.

Costa, J-L., Paulsrud, P., Rikkinen, J. et al., 2001. Genetic diversity of Nostoc symbionts endophytically associated with two bryophyte species. Appl. Environ. Microbiol. 67, 43934396.

Costa, J-L., Paulsrud, P., Lindblad, P., 2002. The cyanobacterial tRNALeu (UAA) intron: evolutionary patterns in a genetic marker. Mol. Biol. Evol. 19, 850-857.

Dal Grande, F., Beck, A., Cornejo, C., Singh, G., Cheenacharoen, S., Nelsen, M.P., Scheidegger, C., 2014. Molecular phylogeny and symbiotic selectivity of the green algal genus Dictyochloropsis s. I. (Trebouxiophyceae): a polyphyletic and widespread group forming photobiont-mediated guilds in the lichen family Lobariaceae. New. Phytol. 202, 455-470.

del Campo, E.M., Catalá, S., Gimeno, J., et al., 2013. The genetic structure of the cosmopolitan three-partner lichen Ramalina farinacea evidences the concerted diversification of symbionts. FEMS Microbiol. Ecol. 83, 310-323.

Dormann, C.F., Gruber, B., Fruend, J., 2008. Introducing the bipartite Package: Analysing Ecological Networks. R News 8, 8-11.

Goward, T., Goffinet, B., Vitikainen, O., 1995. Synopsis of the genus Peltigera (lichenized Ascomycetes) in British Columbia, with a key to the North American species. Can. J. Bot. 73, 91-111.

Grube, M., Wedin, M., 2016. Lichenized Fungi and the Evolution of Symbiotic Organization. Microbiol Spectrum 4(6): FUNK-0011-2016. doi: 10.1128/microbiolspec. 
Grube, M., Cardinale, M., de Castro, J.V. et al., 2009. Species-specific structural and functional diversity of bacterial communities in lichen symbioses. ISME J. 3; 1105-1115.

Elvebakk, A., Papaefthimiou, D., Robertsen E.H., Liaimeret, A., 2008. Phylogenetic patterns among Nostoc cyanobionts within bi- and tripartite lichens of the genus Pannaria. J. Phycol. 44, 1049-1059.

Eriksson, O., Cousins, S.A.O., Bruun, H.H., 2002. Land-use history and fragmentation of traditionally managed grasslands in Scandinavia. J. Veg. Sci. 13, 743-748.

Excoffier, L., Lischer, H.E.L., 2010. Arlequin suite ver 3.5: A new series of programs to perform population genetics analyses under Linux and Windows. Mol. Ecol. Resour. 10, 564-567.

Fedrowitz, K., Kaasalainen, U., Rikkinen, J., 2011. Genotype variability of Nostoc symbionts in three epiphytic Nephroma species in a boreal forest landscape. Bryologist 114, 220-230.

Fedrowitz, K., Kaasalainen, U., Rikkinen, J., 2012. Geographic mosaic of symbiont selectivity in a genus of epiphytic cyanolichens. Ecol. Evol. 2, 2291-2303.

Fernández-Mendoza, F., Domaschke, S., García M.A., Jordan, P., Martín, M.P., Printzen, C., 2011.

Population structure of mycobionts and photobionts of the widespread lichen Cetraria aculeata. Mol. Ecol. 20, 1208-1232.

Helms, G. 2003. Taxonomy and symbiosis in associations of physciaceae and Trebouxia.

Unpublished DPhil Thesis, Göttingen: Georg-August Universität.

Henskens, F.L., Green, T.G., Wilkins, A. 2012. Cyanolichens can have both cyanobacteria and green algae in a common layer as major contributors to photosynthesis. Ann. Bot. 110, 555-563.

Joneson, S., O’Brien, H., 2017. A molecular investigation of free-living and lichenized Nostoc sp. and symbiotic lifestyle determination. Bryologist 120, 371-381.

Jüriado, I., Kaasalainen, U., Rikkinen, J. 2017. Specialist taxa restricted to threatened habitats contribute significantly to the regional diversity of Peltigera (Lecanoromycetes, Ascomycota) in Estonia. Fungal Ecol. 30, 76-87.

Kaasalainen, U., Fewer, D. P., Jokela, J., et al. 2013. Lichen species identity and diversity of cyanobacterial toxins in symbiosis. New Phytol. 198, 647-651.

Kaasalainen, U., Jokela, J., Fewer, D.P., et al., 2009. Microcystin production in the tripartite cyanolichen Peltigera leucophlebia. Mol. Plant. Microb. Interact. 22, 695-702.

Kaasalainen, U., Olsson, S., Rikkinen, J. 2015. Evolution of the tRNA ${ }^{\text {Leu }}$ (UAA) Intron and Congruence of Genetic Markers in Lichen-Symbiotic Nostoc. PLoS ONE 10(6): e0131223. doi:10.1371/journal.pone.0131223. 
Köster, T., Kõlli, R., 2016. Interrelationships between soil cover and plant cover depending on land use. Estonian Journal of Earth Sciences 62, 93-112.

Leavitt S.D., Nelsen, M.P., Lumbsch, H.T., et al., 2013. Symbiont flexibility in subalpine rock shield lichen communities in the Southwestern USA. Bryologist 116, 149-161.

Leavitt S.D., Kraichak, E., Nelsen, M.P., 2015. Fungal specificity and selectivity for algae play a major role in determining lichen partnerships across diverse ecogeographic regions in the lichen-forming family Parmeliaceae (Ascomycota). Molec. Ecol. 24, 3779-3797.

Leppik, E., Jüriado, I., Suija, A., Liira, J., 2013. The conservation of ground layer lichen communities in alvar grasslands and the relevance of substitution habitats. Biodivers. Conserv. 22, 591614.

Leppik, E., Jüriado, I., Suija, A., Liira, J., 2015. Functional ecology of rare and common epigeic lichens in alvar grasslands. Fungal Ecol. 13, 66-76.

Librado, P., Rozas, J., 2009. DnaSP v5: a software for comprehensive analysis of DNA polymorphism data. Bioinformatics 25, 1451-1452.

Lücking, R., Lawrey, J.D., Sikaroodi, M., et al., 2009. Do lichens domesticate photobionts like farmers domesticate crops? Evidence from a previously unrecognized lineage of filamentous cyanobacteria. Am. J. Bot. 96, 1409-1418.

Magain, N., Miadlikowska, J., Goffinet, B., Serusiaux, E., Lutzoni, F., 2017. Macroevolution of specificity in cyanolichens of the genus Peltigera section polydactylon (Lecanoromycetes, Ascomycota). Syst. Biol. 66, 74-99.

Manoharan-Basil, S.S., Miadlikowska, J., Goward, T., Andresson, O., Miao, V.P.W., 2016. Peltigera islandica, a new cyanolichen species in section Peltigera ('P. canina group'). Lichenologist 48, 451-467.

Miadlikowska, J., Lutzoni, F., 2000, Phylogenetic revision of the genus Peltigera (lichen-forming Ascomycota) based on morphological, chemical, and large subunit nuclear ribosomal DNA data. Int. J. Plant Sci. 161, 925-958.

Miadlikowska, J., Lutzoni, F., Goward, T., Zoller, S., Posada, D., 2003. New approach to an old problem: incorporating signal from gap-rich regions of ITS and rDNA large subunit into phylogenetic analyses to resolve the Peltigera canina species complex. Mycologia 95, 11811203.

Miadlikowska, J., Richardson, D., Magain, N., Ball, B., Anderson, F., Cameron, R., Lendemer, J., Truong, C., Lutzoni, F., 2014. Phylogenetic placement, species delimitation, and cyanobiont 
identity of endangered aquatic Peltigera species (lichen-forming Ascomycota, Lecanoromycetes). Am. J. Bot. 101, 1141-1156.

Martínez, I., Burgaz, A.R., Vitikainen, O., Escudero, A., 2003. Distribution patterns in the genus Peltigera Willd. Lichenologist 35, 301-323.

Miao, V.P., Rabenau, A., Lee, A., 1997. Cultural and molecular characterization of photobionts of Peltigera membranacea. Lichenologist 29, 571-586.

Muggia, L., Grube, M., Tretiach, M., 2008. Genetic diversity and photobiont associations in selected taxa of the Tephromela atra group (Lecanorales, lichenised Ascomycota). Mycol. Prog.7, 147-160.

Muggia, L., Zellnig, G., Rabensteiner, J., Grube, M., 2010. Morphological and phylogenetic study of algal partners associated with the lichen-forming fungus Tephromela atra from the Mediterranean region. Symbiosis 51, 149-160.

Muggia, L., Vancurova, L., Skaloud, P., Peksa, O., Wedin, M., Grube, M., 2013. The symbiotic playground of lichen thalli - a highly flexible photobiont association in rock-inhabiting lichens. FEMS Microb. Ecol. 85, 313-323.

Muggia, L., Pérez-Ortega, S., Kopun, T., et al., 2014. Photobiont selectivity leads to ecological tolerance and evolutionary divergence in a polymorphic complex of lichenized fungi. Ann. Bot. $114,463-475$.

Myllys, L., Stenroos, S., Thell, A., Kuusinen. M., 2007. High cyanobiont selectivity of epiphytic lichens in old growth boreal forest of Finland. New Phytol. 173, 621-629.

O’Brien, H. E., Miadlikowska, J., Lutzoni. F., 2005. Assessing host specialization in symbiotic cyanobacteria associated with four closely related species of the lichen fungus Peltigera. Eur. J. Phycol. 40, 363-378.

O’Brien, H. E., Miadlikowska, J., Lutzoni, F., 2013. Assessing population structure and host specialization in lichenized cyanobacteria. New Phytol. 198, 557-566.

Ortiz-Álvarez, R., Rios, A., Fernández-Mendoza, F., Torralba-Burrial, A., Pérez-Ortega, S., 2015. Ecological Specialization of Two Photobiont-Specific Maritime Cyanolichen Species of the Genus Lichina. PLOS ONE 10 (7) DOI: e0132718. https://doi.org/10.1371/journal.pone.0132718.

Otálora, M. A. G., Martínez, I., O’Brien, H., Molina, M.C., Aragon, G., Lutzoni, F. 2010. Multiple origins of high reciprocal specificity at an intercontinental spatial scale among gelatinous lichens (Collemataceae, Lecanoromycetes). Mol. Phylogenet. Evol. 56: 1089-1095. 
Paulsrud, P., Lindblad, P., 1998. Sequence variation of the tRNA Leu intron as a marker for genetic diversity and specificity of symbiotic cyanobacteria in some lichens. Appl. Environ. Microbiol. 64, 310-315.

Paulsrud, P., Rikkinen, J., Lindblad, P., 1998. Cyanobiont specificity in some Nostoc-containing lichens and in a Peltigera aphthosa photosymbiodeme. New Phytol. 139, 517-524.

Paulsrud, P., Rikkinen, J., Lindblad, P., 2000. Spatial patterns of photobiont diversity in some Nostoc-containing lichens. New Phytol. 146, 291-299.

Paulsrud, P., Rikkinen, J., Lindblad, P., 2001. Field investigations on cyanobacterial specificity in Peltigera aphthosa. New Phytol. 152, 117-123.

Pärtel, M., Helm, A., Reitalu, T., Liira, J., Zobel, M., 2007. Grassland diversity related to the Late Iron Age human population density. J. Ecol. 95, 574-582.

Peksa, O., Škaloud, P., 2011. Do photobionts influence the ecology of lichens? A case study of environmental preferences in symbiotic green alga Asterochloris (Trebouxiophyceae). Mol. Ecol. 20, 3936-3948.

Randlane, T., Saag, A. \& Suija, A. 2016. Lichenized, lichenicolous and allied fungi of Estonia. Ver. December 31, 2016 - http://esamba.bo.bg.ut.ee/checklist/est/home.php

R Core Team, 2017. R: A language and environment for statistical computing. R Foundation for Statistical Computing, Vienna, Austria. URL https://www.R-project.org/.

Ramírez-Fernández, L., Zúñiga, C., Méndez, M.A., Carú, M., Orlando, J., 2013. Genetic diversity of terricolous Peltigera cyanolichen communities in different conservation states of native forest from Southern Chile. Int. Microbiol. 16, 243-252.

Rikkinen, J., 2002. Cyanolichens: an evolutionary overview. In: Rai, A.N., Bergman, B., Rasmussen, U. (Eds.), Cyanobacteria in symbiosis. Kluwer Academic Publishers, Netherlands, pp. 31-72.

Rikkinen, J., 2003. Ecological and evolutionary role of photobiont-mediated guilds in lichens. Symbiosis $34,99-110$.

Rikkinen, J., Oksanen, I., Lohtander, K., 2002. Lichen guilds share related cyanobacterial symbionts. Science, 297, 357.

Rikkinen, J., 2013. Molecular studies on cyanobacterial diversity in lichen symbioses. MycoKeys 6, 3-32.

Rikkinen, J., 2015. Cyanolichens. Biodivers. Conserv. 24, 973-993.

Rikkinen, J., 2017. Symbiotic Cyanobacteria in Lichens. In: Grube, M., et al. (Eds.), Algae and Cyanobacteria in Symbiosis. World Scientific Publishing, pp. 147-167. 
Rikkinen, J., Virtanen. V., (2008) Genetic diversity in cyanobacterial symbionts of thalloid bryophytes. J. Exp. Bot. 59, 1013-1021.

Sadowska-Deś, A.D., Dal Grande, F., Lumbsch, T. et al., 2014. Integrating coalescent and phylogenetic approaches to delimit species in the lichen photobiont Trebouxia. Mol. Phylogenet. Evol. 76, 202-210.

Sigurbjörnsdóttir, M.A., Andrésson, Ó.S., Vilhelmsson, O., 2015. Analysis of the Peltigera membranacea metagenome indicates that lichen-associated bacteria are involved in phosphate solubilization. Microbiology 161, 989-996.

Spribille,T., Tuovinen,V., Resl, P. et al., 2016. Basidiomycete yeasts in the cortex of ascomycete macrolichens. Science 10.1126/science.aaf8287.

Stenroos, S., Högnabba, F., Myllys, L., Hyvönen, J., Thell, A., 2006. High selectivity in symbiotic associations of lichenized ascomycetes and cyanobacteria. Cladistics 22, 230-238.

Svenning, M.M., Eriksson, T., Rasmussen, U., 2005. Phylogeny of symbiotic cyanobacteria within the genus Nostoc based on 16S rDNA analyses. Arch. Microbiol. 183, 19-26.

Šmilauer, P., Lepš, J., 2014. Multivariate analysis of ecological data using Canoco 5. Cambridge Univ. Press.

ter Braak, C.J.F., Schaffers, A., 2004. Co-correspondence analysis: A new ordination method to relate two community compositions. Ecology 85, 834-846.

Vargas Castillo, R., Beck, A., 2012. Photobiont selectivity and specificity in Caloplaca species in a fog-induced community in the Atacama Desert, northern Chile. Fungal Biol. 116, 665-676.

Vitikainen, O., 1994. Taxonomic revision of Peltigera (lichenized Ascomycotina) in Europe. Acta Bot. Fenn. 152, 1-96.

Vitikainen, O., 2007. Peltigeraceae. Nordic lichen flora 3, 113-129.

Williams, L., Colesie, C., Ullmann, A., et al., 2017. Lichen acclimation to changing environments: Photobiont switching vs. climate-specific uniqueness in Psora decipiens. Ecol. Evol. 7, 25602574.

Zúñiga, C., Leiva, D., Ramírez-Fernández, L., Carú, M., Yahr, R., Orlando, J., 2015. Phylogenetic diversity of Peltigera cyanolichens and their photobionts in Southern Chile and Antarctica. Microbes Environ. 30, 172-179. 


\section{TABLES}

Table 1. Number of Peltigera taxa, number of Nostoc sequences and genotypes, and genotype diversity $(\mathrm{Hd})$ in combined substratum and habitat groups. Abbrevations of combined variable of substratum and habitat: 'Ground_alvar'=ground in alvars, 'Ground_dune'=ground on dunes, 'Ground_road'=ground in roadside grasslands, 'Ground_eutr'=ground in eutrophic forests, 'Ground_oligotr'=ground in oligotrophic forests, 'Ground_park'=ground in park stands, 'Rock_eutr'=rocks in eutrophic forests, 'Rock_park'=rocks in park stands, 'Tree_eutr'=trees in eutrophic forests.

Substratum and habitat No. of Peltigera taxa No. of Nostoc seqences No. of Nostoc genotypes

Ground_alvar
Ground_dune
Ground_road
Ground_eutr
Ground_oligotr
Ground_park
Rock_eutr
Rock_park
Tree_eutr

$$
10
$$

15

12

12

9

8

8

8

7

40
43
26
19
24
14
9
10
42

42

$\begin{array}{ll}10 & 0.75 \\ 10 & 0.79 \\ 7 & 0.83 \\ 8 & 0.82 \\ 7 & 0.76 \\ 5 & 0.67 \\ 5 & 0.81 \\ 5 & 0.75 \\ 4 & 0.14\end{array}$


Table 2. Results from variation partitioning analysis (VPA), partitioning variance in Nostoc genotypes (presence/absence) found in Peltigera onto two variable sets of 'Mycobiont species' and 'Habitat'. 'Mycobiont species' - 18 taxa of Peltigera (see Supplementary Table 1), 'Habitat' the combined variables of substratum and habitat (see Table 1).

\section{Component $\quad$ Variance explained $\quad \%$ variance explained $\quad \%$ of total variation $\quad F \quad P$}

Unique effect of

'Mycobiont species'

$\begin{array}{ll}4.30 & 69.8\end{array}$

45.6

$5 \quad 0.001$

Unique effect of

'Habitat'

0.67

11.0

7.2

1.50 .001

Shared effect of

'Mycobiont species'

and 'Habitat'

1.18

19.2

12.6

4.70 .001

Total explained

6.15

100

65.3

All variation

9.42

100

$\mathrm{F}$ - F-criterion value, $\mathrm{P}$ - significance level. 


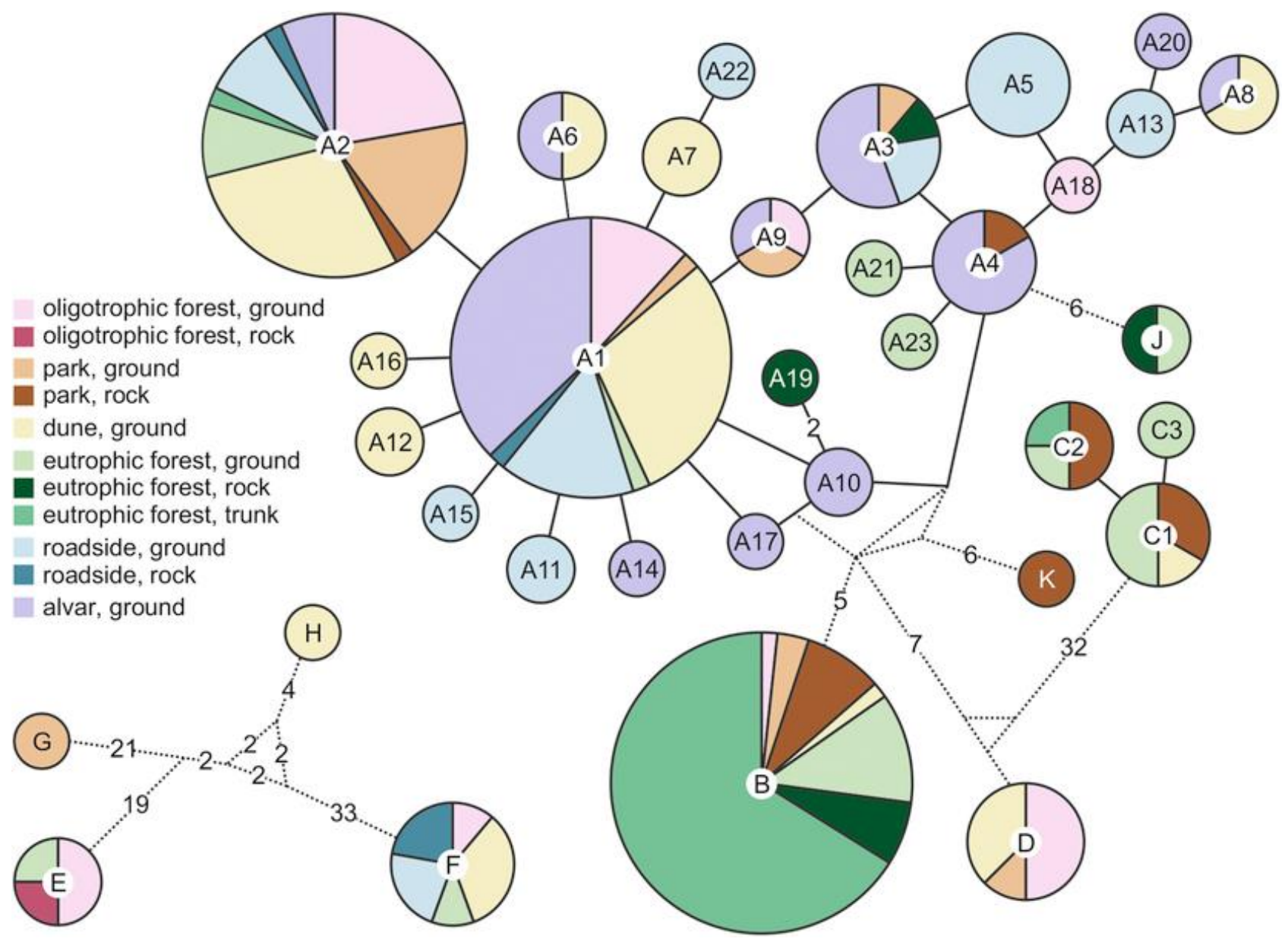

Fig. 1. Nostoc trnL genotype networks. trnL sequences with Class 1 (small network on lower left) and Class 2 (large, on right) P6b regions were analysed separately. The number of single nucleotide differences is shown on connecting lines; genotypes separated by six or more differences are connected via dashed lines and denoted by different letters. The size of each pie chart is proportional to the number of specimens (1-59); the colours of the slices represent different habitats and substrata (light shades indicate ground and dark shades indicate rock). 


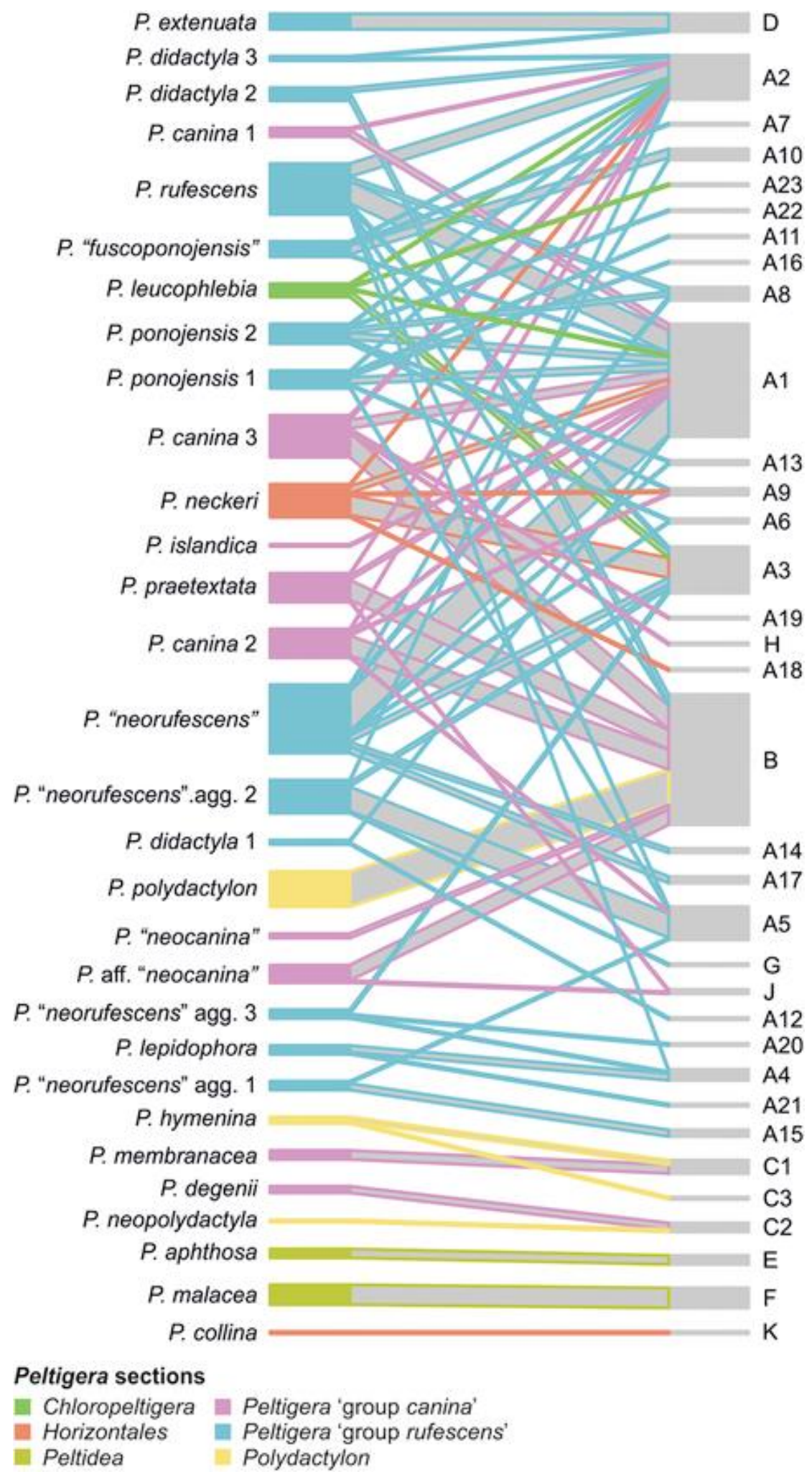

Fig. 2. A bipartite interaction network of Peltigera taxa (on left) and cyanobiont trnL genotypes (on right). Different sections of Peltigera (Miadlikowska and Lutzoni, 2000) and the groups 'canina' and 'rufescens' within the section Peltigera (Juriado et al., 2017) are separated by using different colours. 

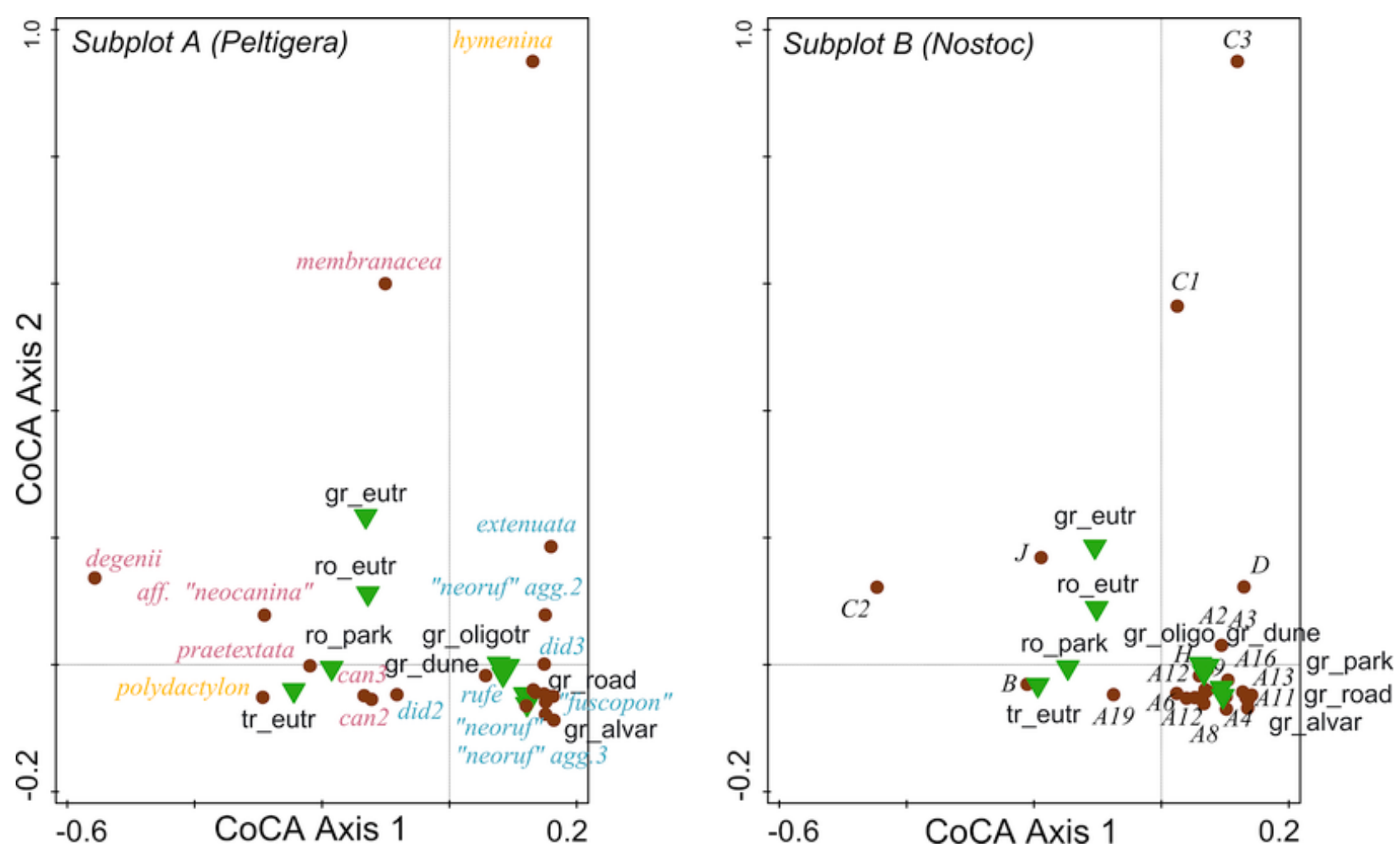

Fig. 3. Symmetric co-correspondence (CoCA) analysis of 22 Peltigera taxa (subplot A) and 26 symbiotic Nostoc genotypes (subplot B). The subplots of the dual diagram show the first two axes (axes 1 and 2), and the environmental descriptors are passively projected into the subplots as filled triangles. Abbreviations of the substrata ' $\mathrm{gr}$ ' $=$ ground, ' $r{ }^{\prime}=$ 'rock, 'tr' $=$ tree. Abbreviations of the habitat types 'alv'=alvar, 'dune'=dunes, 'eutr'=eutrophic forests, 'oligotr'=oligotrophic forests, 'park'=park stands, 'road'=roadside grasslands. Abbreviations of the Peltigera taxa (see Table S1) 'can'=P. canina, 'did'=P. didactyla, 'fuscopon'=P. "fuscoponojensis", 'neoruf'=P. "neorufescens", 'rufe' $=P$. rufescens. Different sections of Peltigera (Miadlikowska and Lutzoni, 2000) and the groups 'canina' and 'rufescens' within the section Peltigera (Juriado et al., 2017) are separated by using different colours as in Fig. 2. 

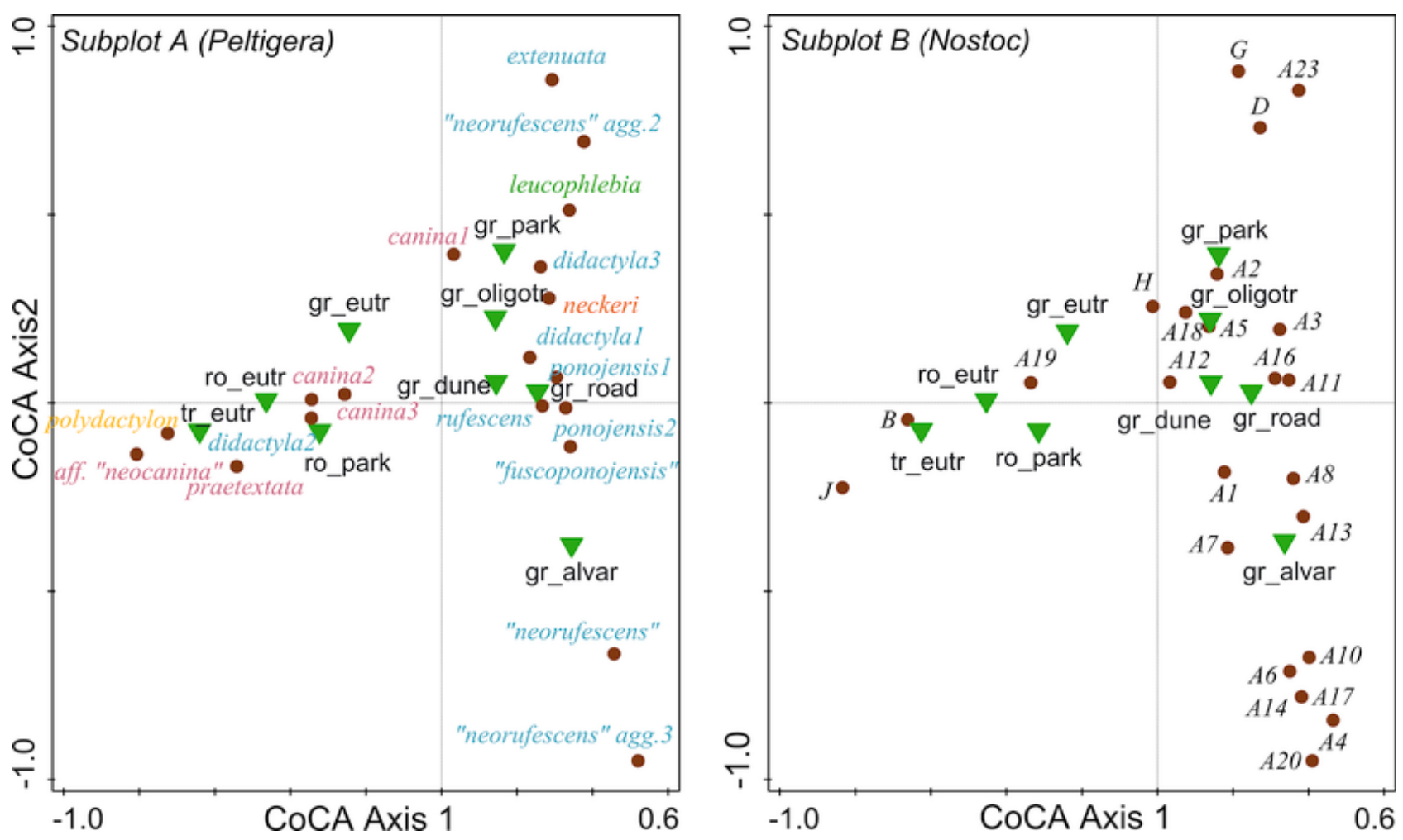

Fig. 4. Symmetric co-correspondence (CoCA) analysis of 19 Peltigera taxa (subplot A) and 24 symbiotic Nostoc genotypes (subplot B). The subplots of the dual diagram show the first two axes (axes 1 and 2), and the environmental descriptors are passively projected into the subplots as filled triangles. Abbreviations of the substrata and habitat types as in Fig. 3. Different sections of Peltigera (Miadlikowska and Lutzoni, 2000) and the groups 'canina' and 'rufescens' within the section Peltigera (Juriado et al., 2017) are separated by using different colours as in Fig. 2. 